\title{
Sociological Analysis of Big Data "Deceive an Acquaintance" Phenomenon in the Internet Era
}

\author{
Chu Jingyu ${ }^{1, *}$ \\ ${ }^{1}$ Institute of Political Science and Law, Jinan University, Jinan, Shandong 250022, China \\ *Corresponding author. Email: 1258836923@qq.com
}

\begin{abstract}
In the Internet era, the application technology of big data is widespread. However, in recent years, the phenomenon of "Deceive an acquaintance" of big data frequently occurs, which has a negative impact on the society. This paper analyzes and summarizes the concept, logic and existing problems of big data "killing the ripe" by combining with relevant cases of big data "killing the ripe", and puts forward relevant governance paths, in order to control the phenomenon of big data "killing the ripe" and maintain a good Internet environment.
\end{abstract}

Keywords: Big data "Deceive an acquaintance", Generation logic, Problem, Governance path

\section{TRADITIONAL "DECEIVE AN ACQUAINTANCE"AND BIG DATA "DECEIVE AN ACQUAINTANCE"}

\subsection{Traditional "Deceive an acquaintance"}

Generally speaking, acquaintances know more about each other than strangers, and their information is relatively symmetrical, so they tend to trust each other more and treat each other with sincerity. As the saying goes, "Make money from acquaintances, eat food from strangers", so in the traditional society of acquaintances, some businesses take advantage of the trust between acquaintances, cheat acquaintances, and the victims are often because of face, willing to be cheated. In the face of some strangers, merchants can no longer play the emotional card, in line with the principle of not losing money, they often give strangers more preferential prices to attract them to buy products. In general, "killing" means that merchants cheat acquaintances out of their money by taking advantage of their acquaintances' trust and relatively weak psychological preparedness to meet their own interests.

\subsection{Big data "Deceive an acquaintance"}

In the context of the Internet, the era of big data has arrived. Big data has brought a lot of convenience to people's lives, but at the same time, it has also brought new problems, that is, big data "kill". Some scholars believe that the so-called "killing" of big data is the price discrimination of old users by merchants using their own user information. [1] Some scholars also believe that big data "killing" refers to a phenomenon that old customers pay higher prices than new customers for the same goods and services. [2] Based on several viewpoints, it can be seen that big data "killing" has the following characteristics: firstly, it is the result of merchants' collecting and sorting out customers' private information by using big data technology; Secondly, it uses the collected information to float the prices of the same products and services to different customers. Third, the target of "kill cooked" is the old customers.

Based on the above characteristics, we can get the definition of "kill the cook" by big data. It is a kind of commercial marketing method that merchants use big data technology to collect and analyze customers' consumption ability and consumption preference, etc., and discriminate the price of old customers for the same kind of goods and services.

\section{THE FENERATION LOGIC OF BIG DATA"DECEIVE AN ACQUAINTANCE"}

\subsection{Problem prototype: precision marketing or differentiated pricing}

In offline stores, all commodities are clearly marked, and all consumers are faced with the same price. Because offline stores do not have consumers' previous consumption data, they do not know consumers' purchase intention, so they dare not risk to modify the price. However, in online e-commerce, merchants can obtain 
data about consumers' purchasing ability, purchasing intention and product preferences through various means, and provide customers with targeted products through analysis and calculation. Therefore, "precision marketing" comes into being. Thus "precise marketing" is in the network environment, using big data technology precision positioning of target market, through the appropriate channels at the right time to the right customer to send the right information, establish communication personalized customer service system, to achieve accurate marketing communication and controllable marketing effect, achieve the low cost expansion of the enterprise. [3]

Precision is similar to the "marketing", some businesses online consumer purchasing power, through the analysis of the technology of data and then learn what consumers to accept the relatively high price of products and relatively low price of the product, to push the appropriate price of goods, this is a "differential pricing", businesses in order to improve their sales and benefit from it, However, the precondition is that commodity prices must be open and transparent, so that consumers have the right to know, otherwise it will be "price discrimination" and "price cheating".

\subsection{Prototype variation: price discrimination or price cheating}

With the increase of profits made by merchants using big data technology, some merchants take advantage of one-way knowledge of consumer information to arbitrarily increase the price of commodities, which is manifested as "price discrimination" and "price cheating". Merchants' "price discrimination" and "price cheating" to consumers are mainly based on two aspects of price increase:

It is according to consumer online search keywords, businesses will search some keywords for the consumer, the paper analyses the frequency and time, which is obtained by analysis are consumers really want to buy the goods, and according to different consumers will develop different pricing schemes, analyse the behaviour of user preferences and consumption ability, the user is accurate "portrait". [4] However, consumers do not know whether the price of the goods they buy is the uniform price of the merchants or the "price discrimination" of the merchants. The second is user stickiness. If consumers frequently purchase goods and services from a certain merchant, it indicates that consumers have strong trust in the merchant. User stickiness is high, and even if the merchant raises the price, consumers will not care too much and may even think that the price is based on the market.

\subsection{What is the nature of it: using trust to gain improper benefits}

Big data "Deceive an acquaintance" means that merchants take advantage of consumers' trust in them, master consumers' consumption habits through big data technology, and raise the price of goods by improper means to obtain improper benefits. Merchant big data "Deceive an acquaintance" of consumers is not for the purpose of improving consumers' consumption experience, but a trust-breaking behavior by taking advantage of consumers' consumption trust and information asymmetry.

\section{PROBLEMS EXISTING IN THE PHENOMENON OF BIG DATA"DECEIVE AN ACQUAINTANCE"}

\subsection{Abuse of big data technology}

Big data technology was originally intended to serve people in need in the Internet era, but the main reason for the proliferation of big data "killing" is the lack of legitimacy and rationality of the purpose of using big data technology. Businesses take advantage of the opacity of big data and the superb collection and analysis ability of big data to collect consumers' privacy information, summarize and analyze consumers' consumption preferences and abilities, and accurately "kill and cook" consumers.

\subsection{Weak awareness of consumer rights protection}

First, the cost of consumers' rights protection is high. The phenomenon of big data "killing" usually exists in some FMCG products, transportation industry and other fields. Consumers usually buy goods and services in these fields more times but with a small amount of money. When consumers through some legal means to protect their legitimate rights and interests, often pay a high time cost, and platform refund amount is often lower than the price of commodities, and consumers are often after buying the goods and services realized that he was "kill", because so many consumers rights to pay costs too much and give up the rights, This has also encouraged businesses to carry out big data "kill cooked" flame.

The legal consciousness of consumers is not sound, and many consumers in the purchase of goods is often ignored the buy interface content at the bottom of the regulations, because buy need to check the rules "read" or "agree to act" and other options, just check the option, did not carefully read the content in the regulations and thus fall into the merchant's "kill" trap.

Individual power is weaker than organizational power, and consumers often lack the awareness and ability of personal privacy protection, which is a common problem 
in China. [5] most consumers for Internet marketers using big data technology behavior is not sensitive to the information of consumers, few realize that it may lead to problems, in addition, consumers may also be because of lack of personal privacy protection ability to take effective measures to safeguard the legitimate rights and interests of oneself, it embodies the consumer individual power is weak, No single individual can protect himself.

\subsection{The laws and regulations are not perfect}

At present, China has no relevant legal provisions specifically aimed at big data "killing", and judicial departments cannot use the law to restrain and control "killing". According to the definition of "killing ripe" of big data summarized in the paper, the author believes that "killing ripe" of big data is a kind of price discrimination or price fraud, which belongs to illegal behavior.

In the face of the current situation, there are several legal issues that need to be addressed. First, the authorization and occupation of data, that is, to solve the data control and user access to the legality of the data; Secondly, it is to solve the problem of how to regulate the way that Internet merchants use data. The third is the protection of consumer's right to privacy and other legitimate rights and interests; Finally, it is the problem of the punishment and industry standard after the occurrence of "killing ripe" behavior.

\section{BIG DATA"DECEIVE AN ACQUAINTANCE"GOVERNANCE PATH}

\subsection{We will strengthen supervision over the use of big data}

The first is to establish a supervision platform for the use of big data to supervise the phenomenon of "overkill" of big data. Using big data technology, analyze and calculate whether there is a big data "kill" motivation and behavior of merchants, and make the analysis and calculation results public. Second, big data inspection departments integrating supervision, review and control should combine with regulatory resources such as industry and information technology departments, industry and commerce departments, public security departments and publicity departments to form a joint regulatory force. Strengthen the supervision of merchants on the use of big data, improve the supervision efficiency, simplify the link of consumer complaints, and provide channels for consumers to complain and report.

\subsection{We will improve relevant laws and regulations}

It is necessary to strengthen the popularization of regulations on e-commerce and pricing in the Pricing Law and other relevant laws to the public, so that the public can understand the national regulations on ecommerce and better safeguard their legitimate rights and interests. Big data "killing" behavior should be strictly defined, fines should be imposed on illegal merchants and costs should be increased, and relevant payment rules and service agreements should be stipulated for merchants to publicize on online platforms. The Law on the Protection of Rights and Interests of Consumers has been added to the Law on the Protection of Rights and Interests of Consumers who have been "killed" by big data, and the procedures for protecting rights of consumers have been simplified, and the ways and means of protecting rights of consumers have been publicized to the public through mass media to facilitate the protection of rights of consumers.

\subsection{Improve consumers' awareness of self- protection}

Internet society although brought us much convenience, but also moment full of traps, such as a barrage of P2P "thunderstorm" events, shocking events results, just like real society, people often preparedness is a stranger on the Internet, neglect of acquaintances, P2P is the use of acquaintances for cheating, which makes us reflect on the way of trust now, That is, to maintain vigilance when dealing with acquaintances in ordinary times. [6] to promote consumer's ego to protect consciousness and self-protection ability, the age of the Internet is filled with a lot of traps, although some consumers in the case of personal privacy is being violated has notice, but it accounts for only part of a few, most consumers of ego to protect consciousness needs to be improved, such as in daily in the network, to meet personal privacy information, Be vigilant and refuse to fill in your personal information when necessary.

In addition, in the Internet big data society, it is necessary to enhance consumers' awareness of prevention of other social members, including acquaintances, through various communication channels. When purchasing goods and services on the network ecommerce, consumers should always observe the price changes to avoid being "killed".

\subsection{Promote standardization of the internal operation of Internet businesses}

Consumers should be the main body of personal information disposal. However, with the development of the Internet and the application of big data technology, consumers have gradually lost the right to control their personal information. Therefore, we should regulate the internal operation of Internet merchants to maintain the power of consumers to control their personal information.

First, information classification standards should be established to strictly distinguish sensitive and nonsensitive information. For example, sensitive information 
such as consumer's ID number, bank card number, mobile phone number and relevant password should be firmly prohibited from collection and sharing. In addition, consent and authorization must be obtained from the information owner, that is, the consumer himself, when collecting information.

The second is to provide consumers with clear and understandable authorization consent for data collection. Under normal circumstances, in order to obtain the authorization of consumers agree that businesses will explain to consumers the purpose of data collection, methods and using range, but in the era of big data, many businesses often use jargon to collect personal information consumers deliberately hide their intentions, authorize under consumer ambiguous attitude. Formulate clear and understandable ethical authorization forms to clearly demonstrate to consumers the scope of data use and the authorization to collect and use.

\section{CONCLUSION}

In the Internet era, the extensive use of big data has brought a lot of convenience to our life. At the same time, while we enjoy the convenience brought by the Internet big data, we are also deeply affected by the conspiracy of big data to "kill and cook". Bad businesses use big data means to "kill" consumers, which seriously damages the legitimate rights and interests of consumers, but also seriously disrupts the order of the network market and the principle of integrity. Therefore, in the face of big data "Deceive an acquaintance" phenomenon, it is necessary to strictly enforce the internal operation of Internet business, strengthen the supervision of the use of big data, improve the relevant legal construction, improve consumers' awareness of self-protection, and resolutely curb the "Deceive an acquaintance" phenomenon of big data.

\section{REFERENCES}

[1] The so-called "big data kill cooked", some people define it as the Internet companies to use their own user data [EB/OL]. HTTP: // https://mini.eastday.com/a/180325093852978.html

[2] Why big data change to "kill" accomplice [EB/OL] http://www.xinhuanet.com/legal/201804/11/c_1122663320.html.

[3] Why does big data "kill the ripe" instead of " kill the living"? [EB/OL] HTTP:// https://www.sohu.com/a/225130356_115207.201803-08/2018-12-01.

[4] Zhao Zhanzheng, Du Xiao, Zhang Guoqing. Industry experts detail the legal points of big data "killing" [N]. Legal Daily,2018-05-23(005).
[5] Delina Miletti. Analysis on the public's privacy protection awareness in the era of big data [J]. Xinjiang Social Science Forum,2017(02):94-97.

[6] Yang Guangfei. "Krypton" : A Facet of Interpersonal Relationship Evolution in Transitional China [J].Academic Communication,2004(05):111-116. 